\title{
Radio echo sounding data analysis of the Shackleton Ice Shelf
}

\author{
Stefano Urbini ${ }^{1,{ }^{\star}}$, Lili Cafarella ${ }^{1}$, Achille Zirizzotti ${ }^{1}$, Ignazio E. Tabacco ${ }^{2}$, Carla Bottari ${ }^{1}$, \\ James A. Baskaradas ${ }^{1}$, Neal Young ${ }^{3}$ \\ ${ }^{1}$ Istituto Nazionale di Geofisica e Vulcanologia, sezione di Roma, Italy \\ ${ }^{2}$ Università degli Studi di Milano, Dipartimento Scienze della Terra, Milano, Italy \\ ${ }^{3}$ Australian Antarctic Division, and Antarctic Climate and Ecosystems Cooperative Research Centre, Hobart, Australia
}

Article history

Received October 9, 2009; accepted July 5, 2010.

Subject classification:

Ice, Ice dynamics, Geomorphology, Instrument and techniques, General or miscellaneous

\section{ABSTRACT}

In this study, our initial results are presented for the interpretation of the radio echo sounding data collected over the Shackleton Ice Shelf and adjacent ice sheet (East Antarctica) during the 2003/2004 AustralianItalian expedition. The Shackleton Ice Shelf is one of the larger ice shelves of the East Antarctic Ice Sheet. The radar survey provided data relating to ice thickness and bed morphology of the outlet glaciers, and thickness of their floating portions. The glacier grounding lines were determined by assessment of the basal echo characters. The information derived is compared with data from the BEDMAP database and from other sources.

\section{Introduction}

The East Antarctic Ice Sheet is the largest ice sheet on Earth, and to date, most of it is poorly explored. Knowledge of its mass balance is needed to determine both the present state of this section of Antarctica and, indeed, of the whole continent, and its role in rising sea levels and global climate change. The mass balance is poorly defined for various reasons. Lack of information on grounding-line positions, ice thickness of outlet glaciers and ice shelves, and their behavior, are among the main sources of error. In addition, logistic constraints, poor coverage of data, and the remoteness of the continent act against its complete definition. Integration of existing datasets with new data collected using various techniques, such as satellite observations, airborne radio echo sounding (RES), groundbased surveys (seismic or RES), and ice cores, are needed to increase our knowledge of this poorly covered area of Antarctica.

Ice shelves comprise about $11 \%$ of the total area of the Antarctic ice sheet, and they contain about $2.5 \%$ of the total ice volume [Drewry 1983]. Moreover, calving contributes to about $80 \%$ of the mass loss from the whole ice sheet [Jacobs et al. 1992, Jacobs et al. 1996]. The retreat and collapse of many ice shelves of the Antarctic Peninsula during recent decades and the dramatic changes that have occurred in West Antarctica have led to open questions about the current status of the East Antarctic ice shelves and their calving [see for example, Skvarca et al. 1999, Scambos et al. 2000, Scambos et al. 2003].

The Shackleton Ice Shelf is one of the larger ice shelves of the East Antarctic Ice Sheet, and it is located between the Mirny $\left(66^{\circ} 33^{\prime} \mathrm{S}, 93^{\circ} 01^{\prime} \mathrm{E}\right)$ and Casey $\left(66^{\circ} 17^{\prime} \mathrm{S}, 110^{\circ} 32^{\prime} \mathrm{E}\right)$ stations of Queen Mary Land (Figure 1). As Rignot [2002] and Zwally et al. [2002] observed, continental ice drains into the Shackleton Ice Shelf mainly through three glaciers: Northcliffe Glacier, Denman Glacier and Scott Glacier. Denman Glacier follows a SW-NE flow direction (parallel to Northcliffe Glacier), and it is the fastest and thickest glacier in the study area. Its speed is about $1,500 \mathrm{~m} \mathrm{yr}^{-1}$ and its thickness at the grounding line is estimated to be around $2,000 \mathrm{~m}$. The calculated mass accumulation and discharge are about $37.4 \pm 9$ and $35.1 \pm 5 \mathrm{~km}^{3}$ ice $\mathrm{yr}^{-1}$, respectively [Rignot 2002, Zwally et al. 2002]. The Scott Glacier, which drains ice along a SE-NW direction from the Knox Coast area, is slower and thinner than the Denman Glacier $(500 \mathrm{~m}$ $\mathrm{yr}^{-1}$ and 1,200 $\mathrm{m}$, respectively); its mass accumulation and discharge values are estimated to be about $10.9 \pm 3$ and 9.2 $\pm 2 \mathrm{~km}^{3}$ ice $\mathrm{yr}^{-1}$ respectively. Overall, the mass balance of the Shackleton Ice Shelf is close to equilibrium, while the whole ice front appears to be retreating landwards [Rignot 2002, Zwally et al. 2002].

The importance of studies of the Shackleton Ice Shelf arises from its proximity to the margin of the continental shelf, while its position as the northern-most Antarctic ice shelf outside the Antarctic Peninsula allows evaluation of its susceptibility in light of global warming.

For Antarctica in general, the BEDMAP database [Lythe et al. 2001] is used as the reference database for ice-thickness data. Unfortunately, the BEDMAP database does not include coverage for this region. However, the Shackleton Ice Shelf 


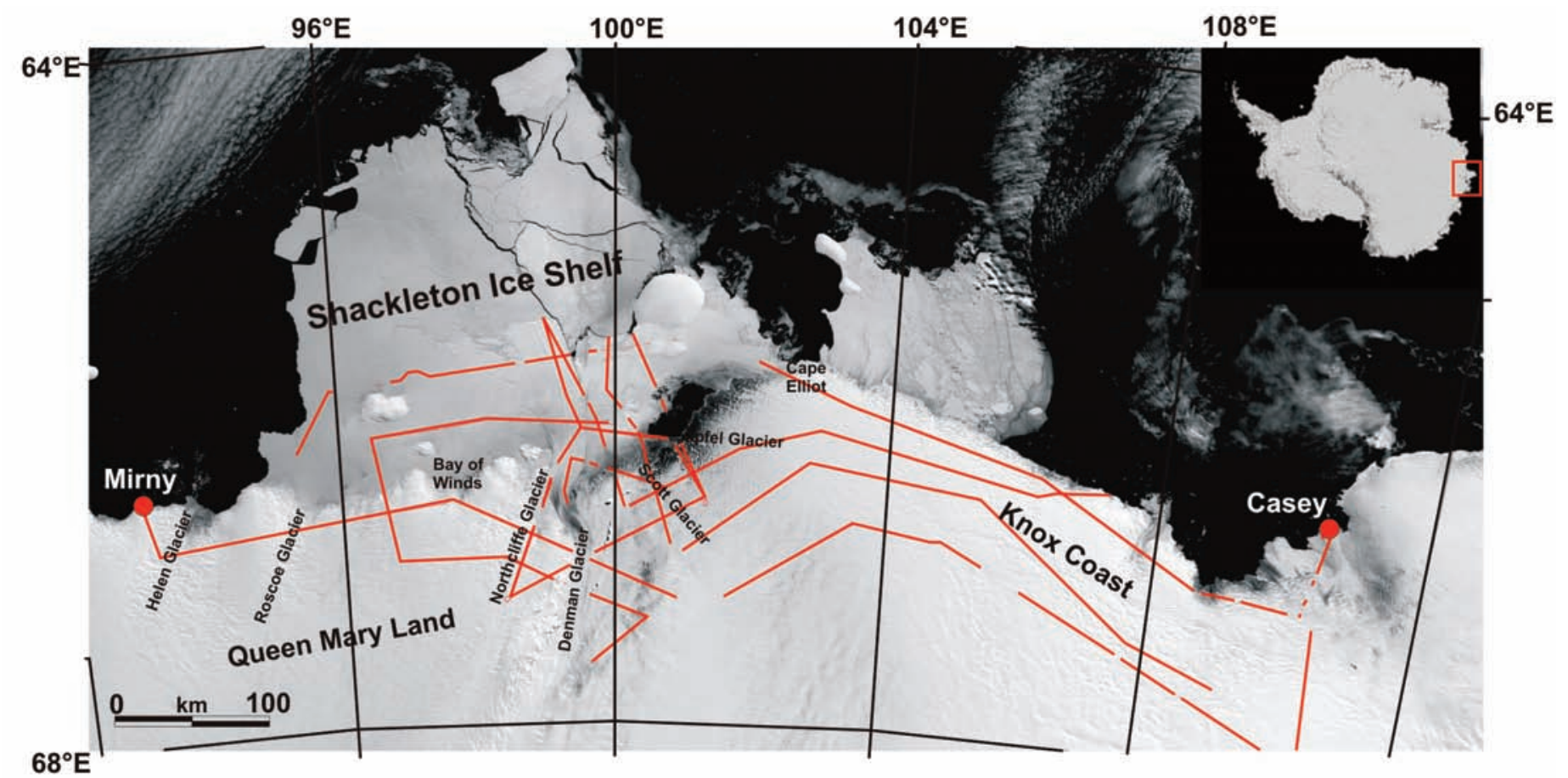

Figure 1. Features around the Shackleton Ice Shelf and its location in Antarctica. The location of the RES dataset is shown as red lines on a MODIS image $(2003 ; 1$ pixel $=250 \mathrm{~m})$.

grounding-line positions have been reviewed recently using interferometric synthetic aperture radar, a remote sensing technique that uses radar satellite images from the European remote-sensing satellite and RADARSAT-1 [Rignot 2002]. This analysis revealed that the present grounding lines differ by some kilometres from their prior positions recorded in the ADD (Antarctic Digital Database; http:/ / www.add.scar.org/) by the Mapping and Geographic Information Centre of the British Antarctic Survey, and in the MODIS (Moderate Resolution Imaging Spectroradiometer) based coastal line (Bohlander and Scambos 2007).

The RES survey presented here was conducted in the framework of the 2003/2004 Australian-Italian Expedition in Antarctica to the Shackleton area, to establish the bedrock topography of local outlet glaciers and the position of grounding lines, and to assess the ice thickness along floating portions of the ice tongues. Figure 1 shows the major features of the study area and its location relative to Antarctica, where the survey lines are shown as red lines superimposed on a MODIS image acquired at 02:50 UT on February 26, 2003 (http:/ / modis.gsfc.nasa.gov).

\section{Materials and methods}

The RES system is an active remote-sensing technique. It uses the penetration of electromagnetic waves into the ice to measure the thickness of ice caps and glaciers, and to obtain information about the internal layering and the characteristics of the basal reflector [Bailey et al. 1964, Whillans 1976, Bogorodsky et al. 1985, Jacobel and Hodge 1995, Milana and Maturano 1999, Tabacco et al. 2000, Plewes and Hubbard 2001, Bianchi et al. 2001].
In the 2003 RES survey, the data were acquired using a pulsed continuous-wave radar system operating at a frequency of $60 \mathrm{MHz}$. The radar system was developed at the Istituto Nazionale di Geofisica e Vulcanologia (INGV) and has been progressively improved since 1997 [Tabacco et al. 1999, Zirizzotti et al. 2008]. The characteristics of the system include a selectable pulse length (between 200 and $1,000 \mathrm{~ns})$, a transmitted peak power of $4 \mathrm{~kW}$, and a pulse repetition rate of 100 traces/s. To increase the signal-to-noise ratio, the average trace is calculated for every 10 traces received, and it is this averaged trace that is recorded. The horizontal spacing between the recorded traces is $7 \mathrm{~m}$, at a mean aeroplane speed of about $220 \mathrm{~km} / \mathrm{h}$. Each recorded trace has 1,280 points at a sampling interval of $50 \mathrm{~ns}$, to give a depth-sampling interval of $4 \mathrm{~m}$ [Tabacco et al. 2008]. The radar system was mounted in a Twin Otter aircraft with separate antennas for transmitting and receiving. Each antenna consisted of a single folded dipole, with one mounted under each wing The ground location of the radar traces was obtained using a Trimble 4000 SSE global positioning system ( $L 1$ and $L 2$ frequencies) equipped with a geodetic antenna mounted on the fuselage, and synchronized with the radar acquisition (with a $\pm 20 \mathrm{~m}$ precision for the $x, y$ coordinates). The values of the surface elevation corresponding to the global positioning system coordinates were extracted from the high-resolution Radarsat Antarctic Mapping Project digital elevation model (RAMPDEM), version 2 [Liu et al. 2001]. The RES survey in the study region consisted of five flights (64 radar profiles) for a total length of about $5,000 \mathrm{~km}$ with a cruise speed of $185-220 \mathrm{~km} / \mathrm{h}$ and an average altitude above the ice surface 
of about $300 \mathrm{~m}$, controlled by radar altimeter.

The ice thickness was calculated using a constant electromagnetic wave propagation velocity of $168 \mathrm{~m} \mu \mathrm{s}^{-1}$ and no firn correction was applied [Glen and Paren 1975, Robin 1975, Bogorodsky et al. 1985, Paterson 1994]. The ice thicknesses were compared at crossover points of all of the radar legs (about 35), to provide a check on internal consistency. More than $70 \%$ of these had ice-thickness differences of less than $40 \mathrm{~m}$. Bed elevation maps were calculated by subtracting the derived ice thicknesses from the RAMPDEM surface elevation values and averaging the resulting values on a grid with a cell size of $8 \mathrm{~km}$ by $8 \mathrm{~km}$, then interpolating using the Kriging gridding method with a linear variogram.

Difficulties arose in the analysis of RADAR echoes, where the signal-to-noise ratio was reduced and where bottom reflections were lost. About $5 \%$ of the line-data could not be used because of this lack of returned echoes from the bedrock. In particular, basal echoes were not received where the surface was heavily crevassed in fastmoving regions. On the ice shelf, we attribute the loss of basal echo in some areas to the presence of large fractures, and also to the presence of marine ice, where the absence of reflections is due to strong attenuation of the RES signal [Souchez et al. 1991, Souchez et al. 1995]. Finally, grounding- line positions were defined as the points where the amplitudes of the reflections changed from those characteristic of an ice/rock interface to those of a meteoricice/sea-water interface.

\section{Main Results}

\section{Bedrock-data analysis}

The analysis of the RES data produced the bedrock elevation map shown in Figure 2, which is again superimposed on a MODIS image. The RES profiles used are shown as black lines on the bedrock map and were only for grounded ice, and the dataset was augmented with elevations of rock outcrops from the ADD. Even though the radar profiles were irregularly distributed over the area analyzed, the resulting map is useful for understanding the general morphology of the region. The features containing the main glacier outlet streams are evident in the data (Figure 2, black dashed lines), and in most cases, their analysis permitted a better understanding of the ice fluxes and the form of the surface topography. The red dashed line in Figure 2 marks a ridge that probably acts as an ice divide between the ice flowing into the Shackleton Ice Shelf and the ice that drains towards the Knox coast. In this area, the bedrock ridge appears to branch to the north, with a valley

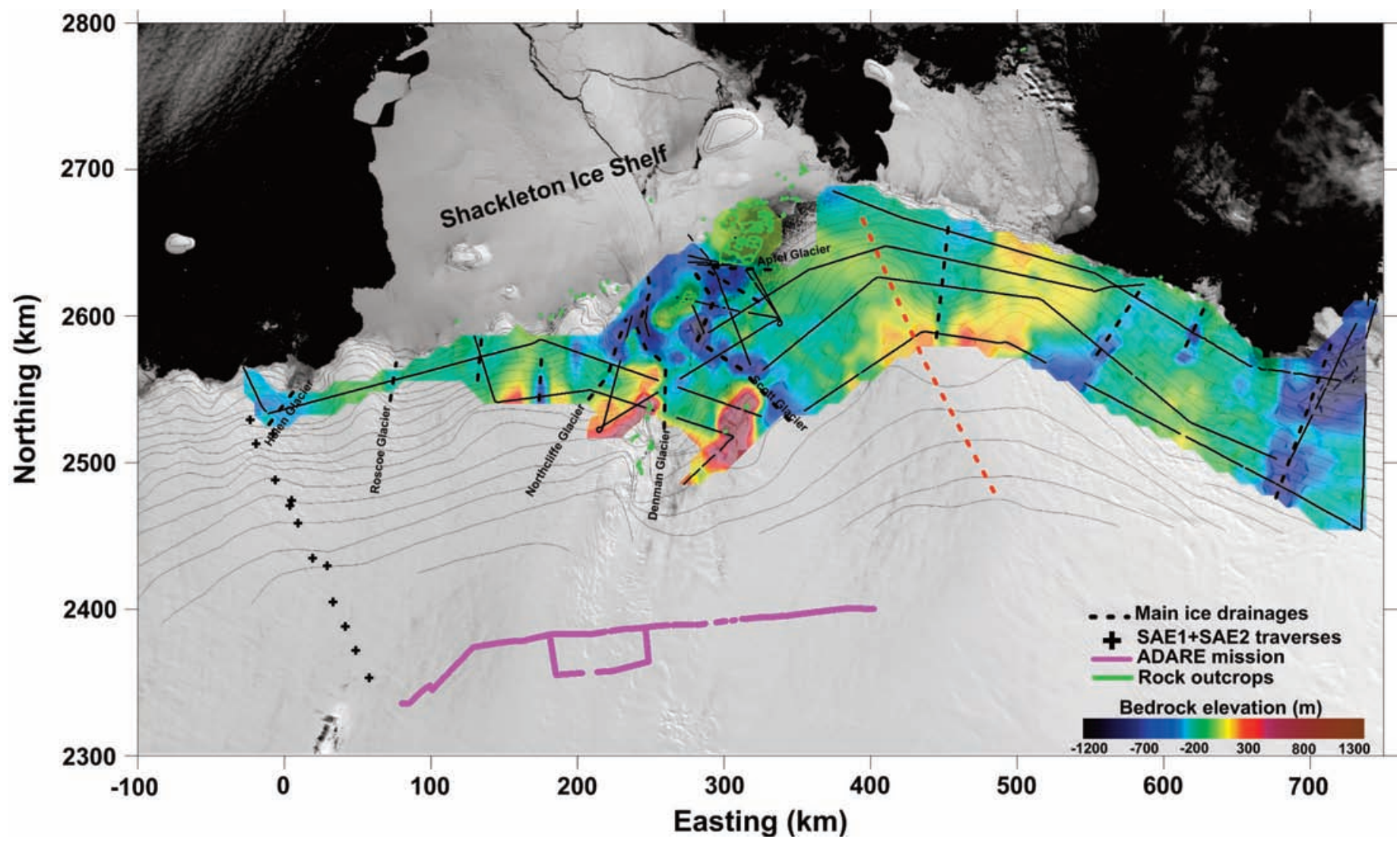

Figure 2. Bedrock elevation map (WGS84). RES profiles of the grounded ice are shown as black lines. Bed-elevation data was calculated as the difference between the RAMPDEM surface elevation and our ice-thickness data. Black crosses and purple lines show positions of nearest BEDMAP data. Red dashed line marks the ridge that probably acts as the divide between ice feeding into the Shackleton Ice Shelf and ice that drains toward the Knox coast. Surface contours are from the ADD; interval, $100 \mathrm{~m}$. 
between the two branches. The valley drains towards the small remaining eastern section of the Shackleton Ice Shelf. The flank of the valley on the east is higher and steeper than on the west. This aspect can also be seen on the corresponding surface topography (Figure 2, thin gray lines).

Data from the BEDMAP archive were also examined to integrate with our data. Unfortunately, there are few data available for the Shackleton Ice Shelf region. However, there are seismic reflection data collected by the Soviet Antarctic Expeditions (SAE 1, 2) in 1956-58 (Figure 2, black crosses), and a RES survey carried out by the Australian Antarctic Division (in 1983 and 1986; Figure 2, purple line). The closest points in our RES and SAE surveys were separated by $13 \mathrm{~km}$, with ice thicknesses of $890 \mathrm{~m}$ and $957 \mathrm{~m}$, respectively. These values are consistent considering the distance between these points.

A study of the outlet glaciers was made by analyzing the RES radargrams for profiles across the glaciers. Three example profiles (Vo25df94, Vo23op71, and Vo23ef63) are shown in a perspective view in Figure 3. For the Northcliffe Glacier and the Denman Glacier, reflections were absent from most of the base (due to heavy surface crevassing) and so they did not allow complete definition of the glacier valley contours. In contrast, the Scott Glacier, which has a lower flow speed than the others, can be defined both in the overall bedrock map, and in more detail by analysis of the threedimensional views of the RES radargrams (Figure 4).

The Scott Glacier is formed from three main ice flows (Figure 4, cyan dotted lines). Ridges separating two of the valleys are visible in section $\mathrm{A}^{\prime}-\mathrm{A}$ in Figure 4, while the third merges with these close to the outlet into the Shackleton Ice Shelf, where they also meet the outlet of the Apfel Glacier.

On the strength of these data, the main ice flow of the Scott Glacier is probably that on the right side of section A'A in Figure 4, which has an ice thickness of about 1,950 m and a width of about $11.7 \mathrm{~km}$. On the left of the main ice flow there is a less deep valley, with an ice thickness of around $1,450 \mathrm{~m}$ that is visible in the map (Figure 4). Both of these streams flow together towards the outlet area, turning right following the valley constraint. In section B-B', the main valley is only partially defined (Figure 4, left end of section). To the right of the main ice stream a narrow ( $4.3 \mathrm{~km}$ wide) and less deep (1.3 km ice thickness) valley is also visible.

Finally, from this analysis of the bedrock map and from the corresponding radargrams, Denman Valley appears to be characterized by an asymmetric shape that is about $9,000 \mathrm{~m}$ wide and of unknown depth. Rignot [2002] estimated the depth as 2,000 $\pm 200 \mathrm{~m}$ at the grounding line in an analysis of the European remote-sensing satellite radar altimetry data.

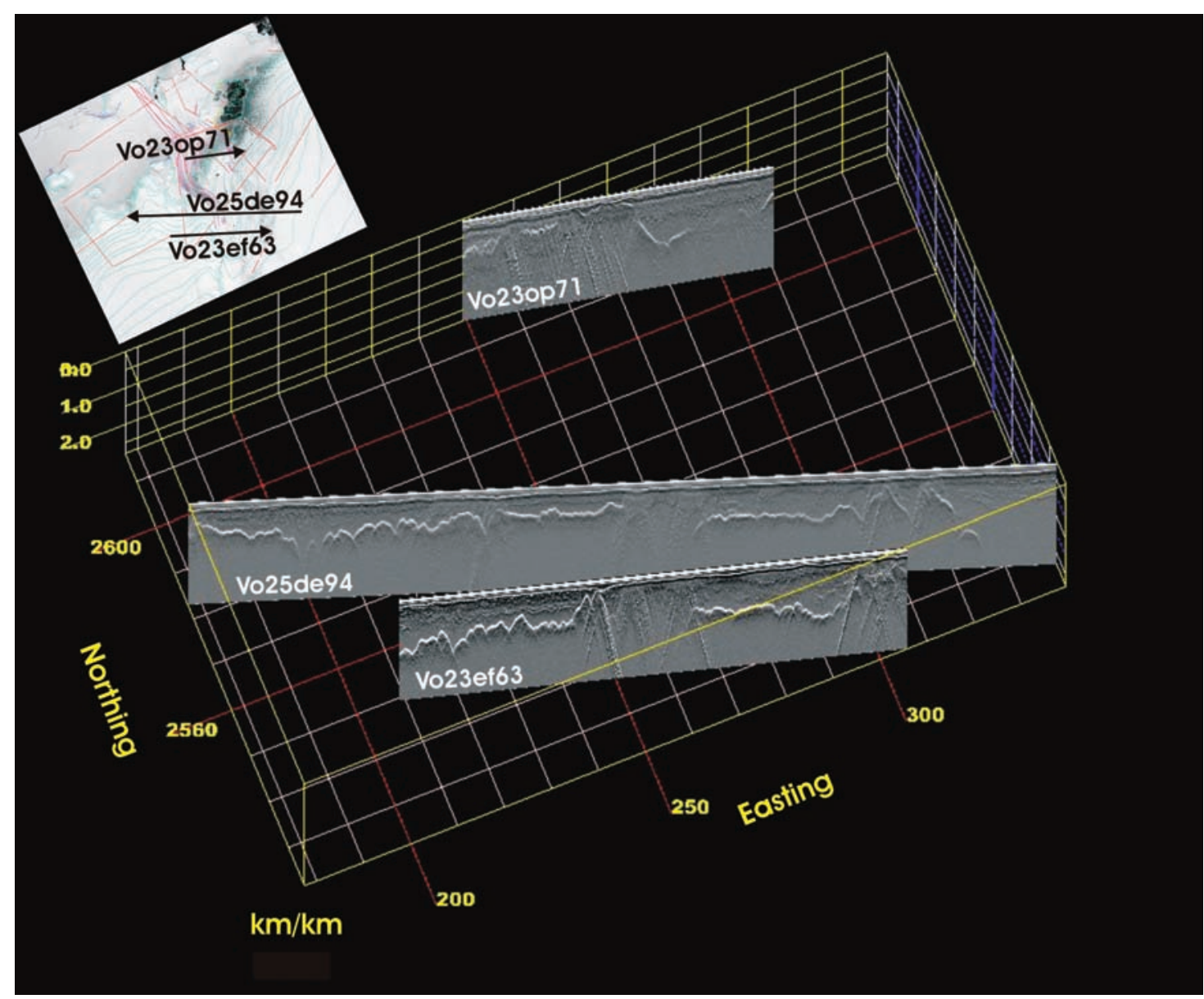

Figure 3. Perspective view of three sections of the RES profiles that cross the Denman Glacier, Vo23op71, Vo25de94 and Vo23ef63, and their projections on the MODIS image. 

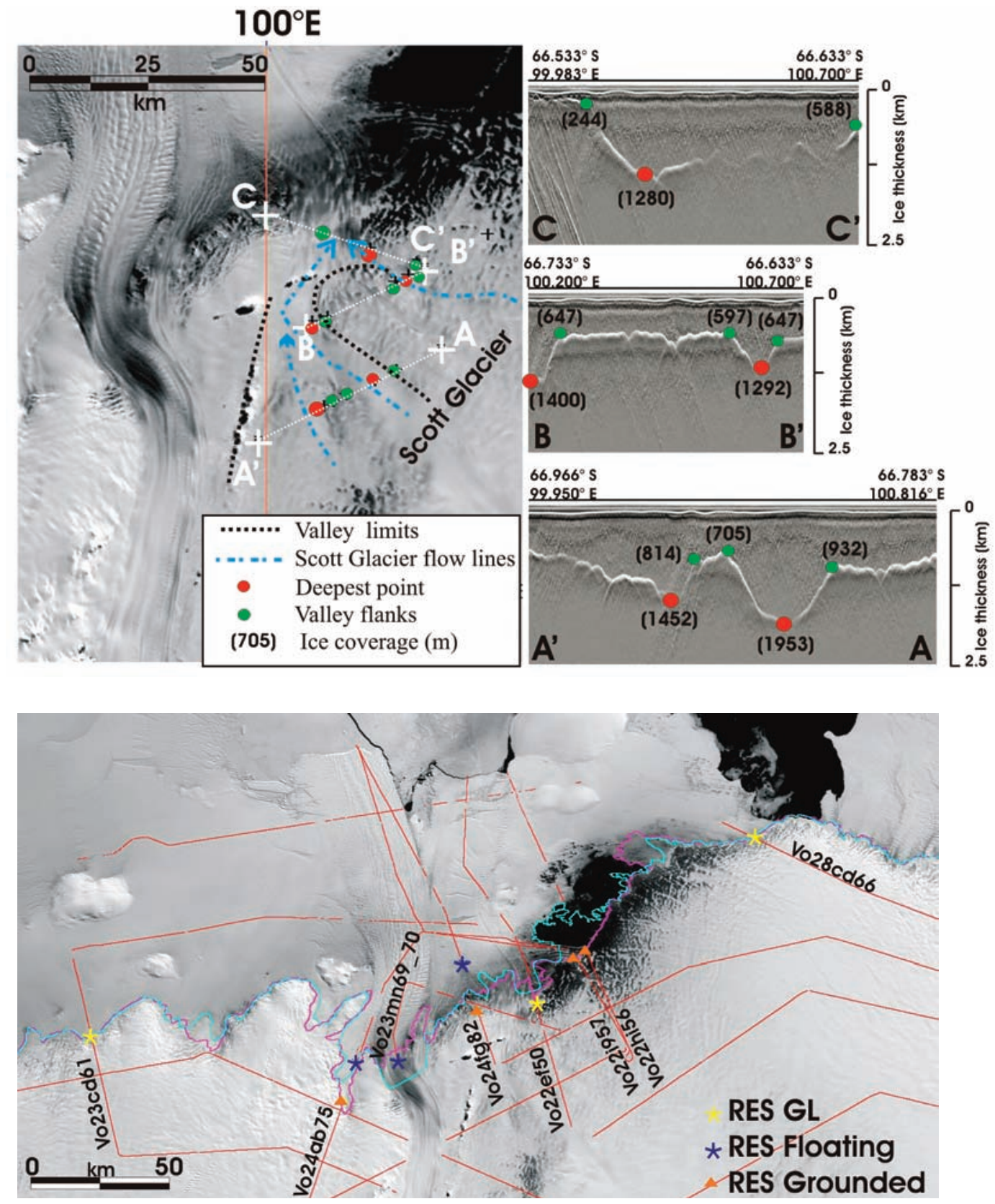

Figure 4 (top). Morphological details of Scott Glacier. The green points indicate valley flanks, and red points indicate the deepest points.

Figure 5 (bottom). Labeled sections of the RES profiles that were analyzed for detection of grounding-line positions; cyan and magenta lines represent the ADD (ver. 3.0) and MOA grounding lines, respectively. Points where reflections from the basal surface of the ice were achieved are plotted in red. Yellow stars show the grounding points deduced from our RES data analysis; blue stars and orange triangles indicate where the ice is grounded on the bedrock and where it is floating, respectively.

\section{Grounding-line positions}

Based on satellite observations, Rignot [2002] and Zwally et al. [2002] have shown the retreating of the outer edge of the Shackleton Ice Shelf (by more than $3 \mathrm{~km} \mathrm{yr}^{-1}$ ) and a more inland position of the floating line on the Denman and Scott Glaciers. To this end, some RES profiles were analyzed to obtain information about grounding-line positions and ice-shelf thickness. In Figure 5, the profiles analyzed for grounding-line detection are shown; here, the yellow stars indicate identified grounding points, while orange triangles and blue stars indicate the end points of profile sections where the ice is grounded on rock and where it is floating, respectively. This discrimination was needed because of data gaps due mainly to the ice conditions of heavy crevassing. For comparison, the grounding lines reported in the ADD and MODIS are shown in Figure 5 as cyan and magenta lines, respectively. The ADD and MOA grounding lines are from interpretations of satellite images in terms of inferred surface slopes and features that might be associated with transition between grounding and floating, and thus these data are indirect. On the other hand, the RES assessment was made on the basis of conditions at the base of the ice, which varies whether the ice is grounded in contact with rock or is floating in contact with sea water, and so these data are more direct. The distances of the RES grounding points from the ADD and MOA reported coastal 


\begin{tabular}{|c|c|c|c|}
\hline Vo23cd61 & $66^{\circ} 36^{\prime} 49^{\prime \prime} \mathrm{S} ; 96^{\circ} 36^{\prime} 56^{\prime \prime} \mathrm{E}$ & $\approx 0$ & $\approx 0$ \\
\hline Vo24ab75 & $\begin{array}{c}\text { Between } \\
66^{\circ} 52^{\prime} 11^{\prime \prime} \mathrm{S} ; 98^{\circ} 49^{\prime} 22^{\prime \prime} \mathrm{E} \\
66^{\circ} 44^{\prime} 55^{\prime \prime} \mathrm{S} ; 98^{\circ} 55^{\prime} 45^{\prime \prime} \mathrm{E}\end{array}$ & $\approx 8^{(1)}$ & $<2^{(2)}$ \\
\hline Vo23mn69_70 & Floating & $\approx 8^{(1)}$ & $\approx 5^{(2)}$ \\
\hline Vo24fg82 & $\begin{array}{c}\text { Between } \\
66^{\circ} 34^{\prime} 05^{\prime \prime} \mathrm{S} ; 100^{\circ} 00^{\prime} 01^{\prime \prime} \mathrm{E} \\
66^{\circ} 24^{\prime} 18^{\prime \prime} \mathrm{S} ; 99^{\circ} 51^{\prime} 41^{\prime \prime} \mathrm{E}\end{array}$ & $\approx 10^{(2)}$ & $\approx 10^{(2)}$ \\
\hline Vo22ef50 & $\begin{array}{l}66^{\circ} 25^{\prime} 38^{\prime \prime} \mathrm{S} ; 100^{\circ} 27^{\prime} 11^{\prime \prime} \mathrm{E} \\
66^{\circ} 28^{\prime} 16^{\prime \prime} \mathrm{S} ; 100^{\circ} 27^{\prime} 14^{\prime \prime} \mathrm{E}\end{array}$ & $\approx 6^{(2)}$ & $\approx 2^{(2)}$ \\
\hline $\begin{array}{l}\text { Vo22hi56 } \\
\text { Vo22i957 }\end{array}$ & $66^{\circ} 00^{\prime} 50^{\prime \prime} \mathrm{S} ; 100^{\circ} 32^{\prime} 30^{\prime \prime} \mathrm{E}$ & $\approx 8^{(2)}$ & $\approx 0$ \\
\hline Vo28cd66 & $65^{\circ} 56^{\prime} 55^{\prime \prime} \mathrm{S} ; 102^{\circ} 21^{\prime} 24^{\prime \prime} \mathrm{E}$ & $<1^{(2)}$ & $\approx 2^{(2)}$ \\
\hline
\end{tabular}

Table 1. Distances from RES grounded/floating points to the ADD and MOA grounding-line positions (apex ${ }^{(1)}$ is for a landward position; while ${ }^{(2)}$ is for a seaward position; GL, grounding line).

lines were calculated and are reported in Table 1.

The profile Vo24ab75 crosses the stream of the Northcliffe Glacier; the end of the grounded data is very close to the area where steep ice meets a flat ice-shelf area. Here, for a long stretch, there were no reflections from the bottom. In this case, the coastline point is located in the data gap, probably closer to the end of the grounded data. In this case, our result is about $8 \mathrm{~km}$ from the position reported in the ADD database supporting the MOA interpretation (less than $2 \mathrm{~km}$ ).

Profile Vo24fg82 crosses the ice shelf and the streams of the Denman and Scott Glaciers. Comparing the RES dataset with the satellite image, it is clear that floating ice bottom reflections disappear at the confluence of the two streams, where crevasses and stressed ice areas are visible in the satellite image. Taking into account that the rock is exposed in the last part of the profile (where data are lacking), the position of the grounding line provided by the ADD and MOA appears to be reasonable.

Again in the case of the profiles Vo22his6 and Vo22i957, the coastline points cannot be evaluated precisely. The lack of data, the emergence of the rock surface, and the presence of a small ice-covered island prevent the identification of the position of the grounding line. However, it probably needs to be shifted southwards relative to the position reported in the ADD.

For the profile Vo23mn69_70, only reflections from the bottom of floating ice were obtained from the RES data analysis. In this case, our results suggest that the coastline should be positioned more upstream in the Denman ice stream with respect to the information provided by the MOA database.

The analysis of profiles Vo22ef50, Vo23cd61 and Vo28cd66 allowed the determination of the position of the grounding lines, which show good agreement with both of the databases, except for the ADD on Vo22ef50. It is important to note here that the definition of the grounding-line positions by MOA match our RES data better than the ADD dataset.

In addition, the study of the RES profiles Vo23cd61 and Vo28cd66 provided important information about the morphology of the grounding-point contact. In particular, detailed analysis of profile Vo23cd61 (Figure 6a) allowed the definition of the boundary between the ice/seawater and ice/bedrock systems (Figure 6a, $G$ ), which was suggested by the abrupt changes in the RES signal amplitude. Looking at the final interpretation, in which the profiles of the surface and rock elevations are presented (Figure 6b), and taking into account material reported by other studies [Rignot 2002, Bohlander and Scambos 2007], other typical grounding-line morphology points have been estimated. In particular, Figure $6 \mathrm{~b}$ indicates the "hydrostatic limit» $(H)$, the "break in slope» point $(I b)$ and the "limit of flexure» $(F)$. Finally, some other interesting observations can be made: the ice thickness varies along the profile from about $300 \mathrm{~m}$ to $600 \mathrm{~m}$, and then it gets thinner again towards the coast. These variations can lead to the generation of bottom fractures in the ice shelf. These are shown as small hyperbolas in the radargrams and as short features in the blue circle in the profile in Figure $6 \mathrm{a}$. 

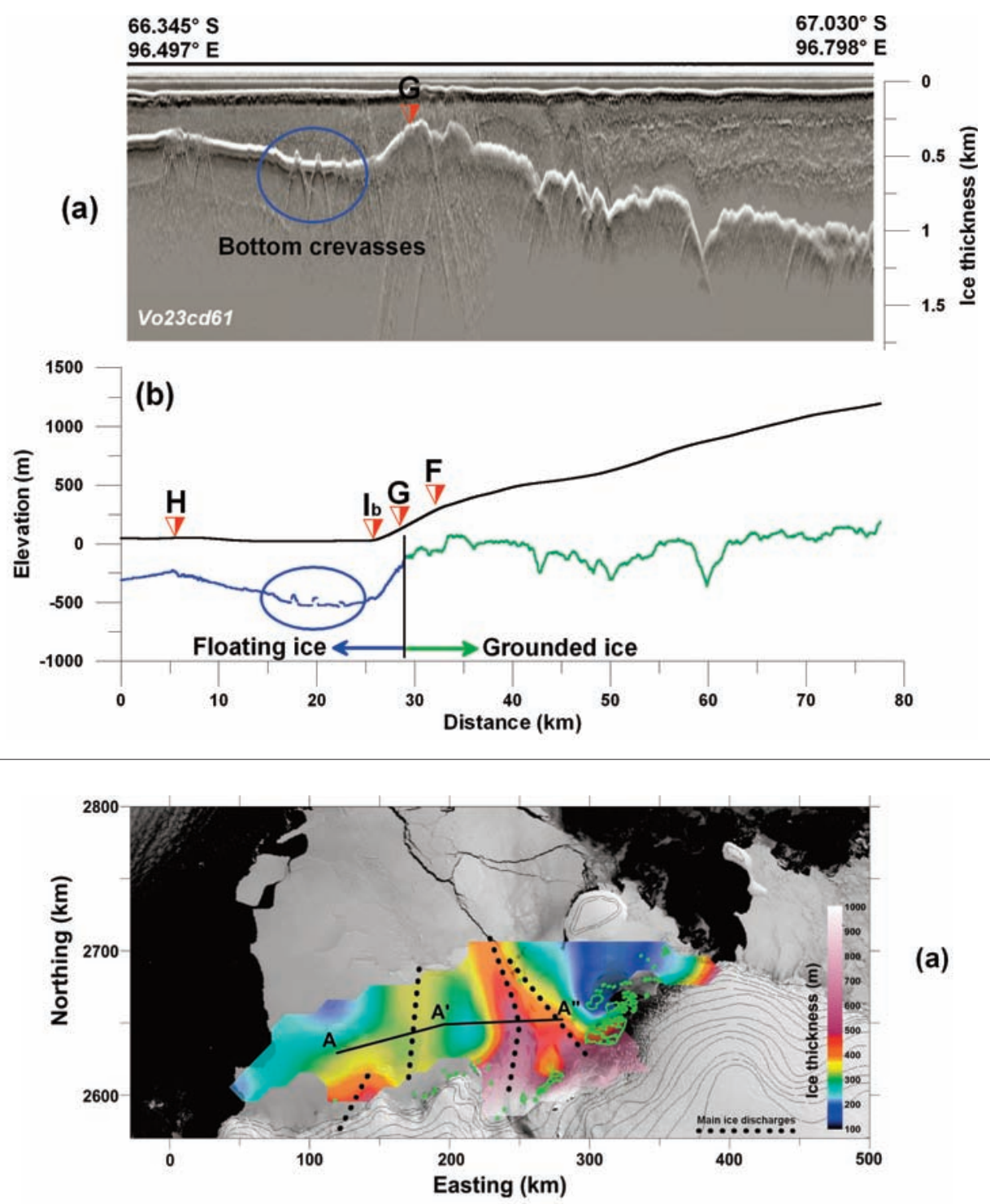

(a)

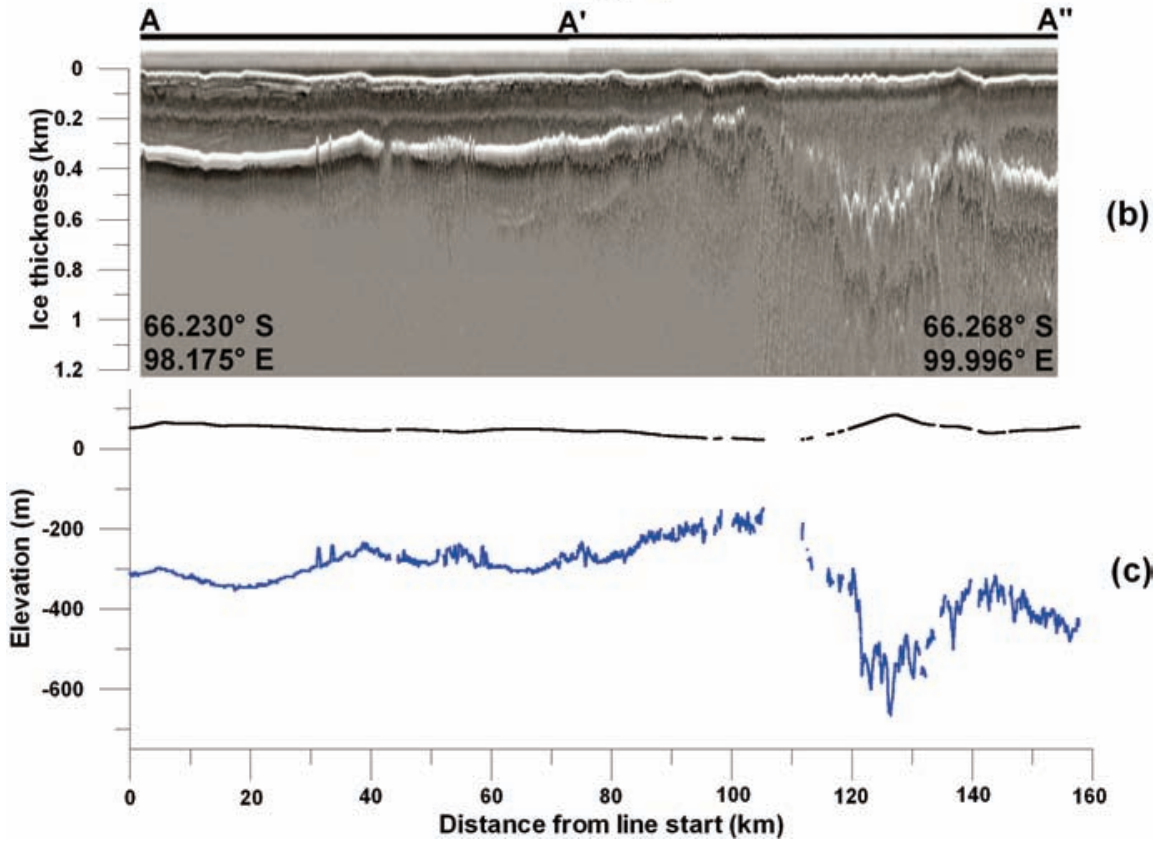

Figure 6 (top). The RES profile Vo23cd61 (a) and the morphological analysis of its grounding point (b). G indicates the boundary separating floating ice (ice in contact with sea water) from grounded ice (ice in contact with rock), $H$ is the «hydrostatic limit», $I_{b}$ is the «break in slope» point, and $F$ is the «limit of flexure». Blue circle/ellipse: bottom fractures in the ice shelf.

Figure 7 (bottom). Analysis of the Shackleton Ice Shelf ice thickness. (a) map showing the spatial distribution of the ice thickness interpolated from the RES data; (b) RES data presented as a radargram along section A-A'-A"; (c) Profile of ice thickness extracted by analysis of the radargram along section A-A'-A". 


\section{Ice-shelf thickness}

Assessment of the thickness of the Shackleton Ice Shelf was another aim of this RES survey. In Figure 7a, the spatial distribution of ice thickness is shown together with the sections of the RES profiles corresponding to floating ice, where the thick ice in the streams of the Denman and Scott Glaciers at their confluence is visible. The A-A'-A" sections in Figure $7 \mathrm{a}, \mathrm{b}$ show the results along a RES profile intersecting the main ice-discharge streams. Looking at the corrected topography profile shown in Figure $7 c$, it is evident that the thickness of the ice shelf measured has a mean value of about $300 \mathrm{~m}$. Proceeding along line A, the ice thickness shows small variations that are associated with local glacier flows, until the point in which the profile intercepts the Denman Glacier flow (110 km from the origin of the line). From there, the ice thickness reduces to half of its initial value for a short stretch, and the amplitude of the basal echoes changed dramatically. This effect is probably due to the presence of fractures in the ice bed, with the transition from a smooth interface (ice shelf) to a rough one (glacier flow with basal crevasses). Then the thickness (about in the middle of the stream) increases to more than $600 \mathrm{~m}(127 \mathrm{~km}$ from the origin of the profile), with an associated change in the ice surface topography. The thickness then drops over the following 2-3 km, where rock outcrops obstruct the ice flow, then it increases again, reaching the point of the confluence of the Scott and Apfel Glaciers.

\section{Conclusions}

In this study, we present the data of the 2003/2004 Antarctic RES survey on the Shackleton Ice Shelf, between the Mirny $\left(66^{\circ} 33^{\prime} \mathrm{S}, 93^{\circ} 01^{\prime} \mathrm{E}\right)$ and Casey $\left(66^{\circ} 17^{\prime} \mathrm{S}, 110^{\circ} 32^{\prime} \mathrm{E}\right)$ stations. The purpose of the survey was the determination of the morphology of the sub-glacial rock and the local outlet glaciers, and the position of grounding lines, and the assessment of the ice thickness along the floating portions of the ice tongues.

The bedrock map revealed the general morphology of the region and the main characteristics of the erosion in the glacier outlet confluence area. Analysis of the radargrams showed that bottom reflections were sometimes lost where the surface was heavily crevassed and stressed because of the drainage of a large ice-mass in a narrow, deep valley. Due to this effect, only the Scott Glacier valley was well described, while the other two, for the Denman and Northcliffe Glaciers, were not clearly defined.

This analysis of the longitudinal and transverse profiles over the ice streams has provided important information about the grounding-line positions and about the ice-shelf thickness. Grounding-line positions and monitoring of iceshelf motion are destined to have even more important roles as response effects to global climate change. In some cases, our coastline positions correspond to the values in the ADD and MODIS databases. In one case, only a small difference was found (line Vo24ab75); however, for the remaining files analyzed (Vo23mn69-Vo23no70 and Vo22ef50), our data show large differences.

Finally the analysis of some RES profiles showed that the ice-shelf thickness is relatively constant, varying from about $200 \mathrm{~m}$ to $300 \mathrm{~m}$, except in the confluence of the Denman, Scott and Apfel streams, where they meet the ice shelf. Here the ice thickness reaches about $600 \mathrm{~m}$, which is associated with changes in the ice surface topography.

Improved bedrock modeling based on the RES dataset and detailed analysis of ice-shelf profiles, combined with ICESat observations, will contribute to a better understanding of the Shackleton Ice Shelf dynamics.

Acknowledgements. This study was carried out within the framework of the Project of Glaciology of the PNRA (Italian Antarctic Project) and at the Antarctic Climate \& Ecosystems Cooperative Research Centre, supported by the Australian Government's Cooperative Research Centres Program. Logistic support was provided by the Australian Antarctic Division. The authors wish to thank two anonymous referees for their useful suggestions and critical observations, and the Australian expedition members at Casey and Davis stations for their hospitality and assistance.

\section{References}

Bailey, J.T., S. Evans and G. De Q. Robin (1964). Radio echo sounding of polar ice sheets, Nature, 204, 420-21.

Bianchi, C., M. Chiappini, I.E. Tabacco, A. Passerini, A. Zirizzotti and E. Zuccheretti (2001). Morphology of bottom surfaces of glacier ice tongues in the East Antarctic region, Annals of Geophysics, 44 (1), 127-135.

Bogorodsky, V. V., C.R. Bentley and R. Gudmandsen (1985). Radioglaciology, Dordrecht, 254 pp.

Bohlander, J. and T. Scambos (2007). Antarctic coastlines and grounding line derived from MODIS Mosaic of Antarctica (MOA), Boulder, Colorado USA: National Snow and Ice Data Center (digital media, accessed April 24, 2008).

Drewry, D.J. (1983). Glaciological and geophysical folio, Internal layering in the Antarctic ice sheet, Sheet 9 of Antarctica, Cambridge: Scott Polar Research Institute.

Glen, J.W. and J.G. Paren (1975). The electrical properties of snow ice, J. Glaciol., 151, 15-37.

Jacobel, R.W. and S.M. Hodge (1995). Radar internal layers from Greenland summit, Geophys. Res. Lett., 22, 587-590.

Jacobs, S.S., H.H. Hellmer, C.S.M. Doake, A. Jenkins and R.M. Frolich (1992). Melting of ice shelves and the mass balance of Antarctica, J. Glaciol., 38, 375-387.

Jacobs, S.S., H.H. Hellmer and A. Jenkins (1996). Antarctic ice sheet melting in the southeast Pacific, Geophys. Res. Lett., 23, 957-960.

Liu, H., K. Jezek, B. Li and Z. Zhao (2001). Radarsat Antarctic Mapping Project digital elevation model, version 2, Boulder, Colorado USA: National Snow and Ice Data Center (digital media, accessed October 1st, 2001). 
Lythe, M.B., D.G. Vaughan and the BEDMAP Consortium (2001). BEDMAP: A new ice thickness and subglacial topographic model of Antarctica, J. Geophys. Res., 106, 11,335-11,351, doi:10.1029/2000JB900449.

Milana, J.P. and A. Maturano (1999). Application of radio echo sounding at the arid Andes of Argentina: the Agua Negra Glacier, Global Planet. Change 22, 179-191.

Paterson, W.S.B. (1994). The physics of glaciers, 3rd edition, Oxford, New York, Tokyo, 480 pp.

Plewes, L. and B. Hubbard (2001). A review of the use of radio-echo sounding in glaciology, Prog. Phys. Geog., 25, 203-236.

Rignot, E. (2002). Mass balance of East Antarctic glaciers and ice shelves from satellite data, Ann. Glaciol., 34, 217-227.

Robin, G. de Q. (1975). Velocity of radio waves in ice by means of a bore-hole interferometric technique, J. Glaciol., 15, 151-159.

Scambos, T.A., C. Hulbe, M. Fahnestock and J. Bohlander (2000). The link between climate warming and break-up of ice shelves in the Antarctic Peninsula, J. Glaciol., 46 (154), 516-530.

Scambos T., C. Hulbe and M. Fahnestock(2003). Climateinduced ice-shelf disintegration in the Antarctic Peninsula, Antarct. Res. Ser., 79, 79-92.

Souchez, R., M. Meneghel, J.L. Tison, R. Lorrain, D. Ronveaux, C. Baroni, A. Lozej, I.E. Tabacco and I. Jouzel (1991). Ice composition evidence of marine ice transfer along the bottom of a small Antarctic ice shelf, Geophys. Res. Lett., 18, 849-852.

Souchez, R., J.-L. Tison, R. Lorrain, C. Fléhoc, M. Stiévenard, J. Jouzel, V. Maggi (1995). Investigating processes of marine ice formation in a floating ice tongue by a high resolution isotopic study, J. Geophys. Res., 100, 7019-7025.

Skvarca, P., W. Rack and H. Rott (1999). 34 year satellite time series to monitor characteristics, extent and dynamics of Larsen B, Antarctic Peninsula, Ann. Glaciol., 29, 255-260.

Tabacco, I.E., C. Bianchi, M. Chiappini, A. Passerini, A. Zirizzotti and E. Zuccheretti (1999). Test improvements for the echo sounding system of the Italian radar glaciological group and measurements in Antarctica, Annals of Geophysics, 42, 271-276.

Tabacco, I.E., C. Bianchi, M. Chiappini, A. Zirizzotti and E. Zuccheretti (2000). Analysis of bottom morphology of the David Glacier-Drygalsky Ice Tongue, East Antartica, Ann. Glaciol., 30, 47-51.

Tabacco, I.E., C. Bianchi, J.B. Arokiasamy, L. Cafarella, U. Sciacca, A. Zirizzotti and E. Zuccheretti (2008). Italian RES investigation in Antarctica: the new radar system, Terra Antartica Rep., 14, 213-216.

Whillans, I.M. (1976). Radio echo layers and recent stability of the West Antarctic ice sheet, Nature, 264, 152-155.

Zirizzotti, A., J.A. Baskaradas, C. Bianchi, U. Sciacca, I.E. Tabacco and E. Zucheretti (2008). Glacio RADAR system and results, Radar Conference, 2008. RADAR '08. IEEE, $26,1-3$.

Zwally, H.J., M.A. Beckley, A.C. Brenner and M.B. Giovinetto (2002). Motion of major ice-shelf fronts in Antarctica from slant-range analysis of radar altimeter data, 197898, Ann. Glaciol., 34, 255-262.

\footnotetext{
${ }^{\star}$ Corresponding author: Dr. Stefano Urbini, Istituto Nazionale di Geofisica e Vulcanologia, sezione di Roma, Italy; e-mail: stefano.urbini@ingv.it
}

(C) 2010 by the Istituto Nazionale di Geofisica e Vulcanologia. All rights reserved. 